\title{
A Simple Calculation of Dielectric Loss from Dielectric Dispersion for Polar Polymers
}

\author{
Paul Ehrlich
}

\begin{abstract}
For polar polymers undergoing orientation polarization it is possible to calculate dielectric losses from dielectric constant data by use of a single approximation already familiar from its application to mechanical properties, if this approximation is applied to the real part of the dielectric constant only and if data over a sufficiently wide frequency range are available. Data obtained at frequencies from $10^{2}$ to $10^{8}$ cycles per second for Butvar and for a copolymer of styrene and methyl methacrylate are analyzed and it is found that observed and calculated values of the dielectric losses agree within 10 percent or better.
\end{abstract}

Equations relating the real and the imaginary parts of the dielectric constant have been given, but are not in general use because the equations involved are cumbersome $[1,2,3] .^{1} \quad$ Workers interested in the mechanical behavior of high polymers have shown how the real and the imaginary parts of the modulus of rigidity are related through a distribution function [4] and how this function can be obtained by an approximation method from the real part of the modulus $[5,6]$ and from both real and imaginary parts [7]. It will be shown how the dielectric loss can be calculated from dielectric constant data by an analogous approximation method.

The Debye equations [8], generalized for a distribution of capacitance elements with resistance elements in parallel [9], each with its characteristic relaxation time, mathematically equivalent to a mechanical retardation time, are

$$
\begin{gathered}
\epsilon^{\prime}-\epsilon_{\infty}=\int_{0}^{\infty} \frac{y(\tau) d \tau}{1+\omega^{2} \tau^{2}} \\
\epsilon^{\prime \prime}=\int_{0}^{\infty} \frac{\omega \tau y(\tau) d \tau}{1+\omega^{2} \tau^{2}}
\end{gathered}
$$

where $\epsilon^{\prime}, \epsilon^{\prime \prime}$ are the real and the imaginary parts of the dielectric constant, $\omega$ is the angular frequency, $\tau$ is the relaxation time and $y(\tau)$ is the distribution of relaxation times. For mathematical convenience, we define $y(\tau) d \tau=Y(\ln \tau) d \ln \tau$. The cut-off approximation $[5,6,7]$ assuming the integrands in (1a), (1b) to vanish for $\omega \tau>1$ and to reduce to their numerators for $\omega \tau \leq 1$ gives

$$
\begin{gathered}
\epsilon^{\prime}-\epsilon_{\infty}=\int_{-\infty}^{\ln \frac{1}{\omega}} Y(\ln \tau) d \ln \tau \\
\epsilon^{\prime \prime}=\int_{-\infty}^{\ln \frac{1}{\omega}} \omega \tau Y(\ln \tau) d \ln \tau .
\end{gathered}
$$

(2a) gives agreement with (1a) well within the graphical error involved in the calculations, whereas values of $\epsilon^{\prime \prime}$ calculated from (2b) are generally 30 to 40 percent low when compared to those obtained from

\footnotetext{
${ }^{1}$ Figures in brackets indicate the literature references at the end of this paper
}

(1b). We therefore use the approximation (2a) only. obtaining

$$
Y\left(\ln \frac{1}{\omega}\right)=-\frac{d \epsilon^{\prime}}{d \ln \omega}
$$

by differentiation of (2a) with respect to the upper limit and carry out this operation graphically. The exact eq $(1 b)$ is then used to obtain $\epsilon^{\prime \prime 2}$ by a graphical integration for each value of $\omega$. The integration is done graphically, because even the most widely applicable equations that have been suggested for $y(\tau)$ on semiempirical grounds $[2,10]$ and that might have been expected to represent the results cited do not fit the data over the entire frequency range and because, if the curve for $Y(\ln \tau)$ is approximated in sections by simple analytical expressions, integration often becomes impossible.

Data are presented over a wide frequency range, including either side of the absorption maximum, for Butvar (polyvinylbutyral) [11], a material which, for an unplasticized polymer, has a fairly sharp dispersion and for SM-2, a copolymer with a broad dispersion made from 49-mole-percent styrene and 51mole-percent methyl methacrylate; both polymers

\begin{tabular}{|c|c|c|c|c|c|}
\hline Frequency & $\epsilon^{\prime}$ & $\epsilon^{\prime \prime}$ & $Y$ & $-\log \tau$ & $\begin{array}{l}\epsilon^{\prime \prime}(\text { cal- } \\
\text { culated) }\end{array}$ \\
\hline $\begin{array}{l}10^{2} \quad c / s \\
4 \times 10^{2} \\
10^{3} \\
3 \times 10^{3} \\
10^{4}\end{array}$ & $\begin{array}{l}3.415 \\
3.394 \\
3.382 \\
3.364 \\
3.336\end{array}$ & $\begin{array}{r}0.0238 \\
.0271 \\
.0301 \\
.0387 \\
.0550\end{array}$ & $\begin{array}{r}0.0130 \\
.0152 \\
.0200 \\
.0243 \\
.0317\end{array}$ & $\begin{array}{l}2.80 \\
3.40 \\
3.80 \\
4.275 \\
4.80\end{array}$ & $\begin{array}{r}0.032 \\
.041 \\
.056\end{array}$ \\
\hline $\begin{array}{l}3 \times 10^{4} \\
10^{5} \\
3 \times 10^{5} \\
10^{6} \\
3 \times 10^{6}\end{array}$ & $\begin{array}{l}\text { 3. } 307 \\
3.233 \\
3.170 \\
3.075 \\
2.988\end{array}$ & $\begin{array}{l}.0788 \\
.104 \\
.110 \\
.111 \\
.101\end{array}$ & $\begin{array}{l}.0433 \\
.062 \\
.073 \\
.078 \\
.073\end{array}$ & $\begin{array}{l}5.275 \\
5.80 \\
6.275 \\
6.80 \\
7.275\end{array}$ & $\begin{array}{l}.073 \\
.094 \\
.107 \\
.114 \\
.111\end{array}$ \\
\hline $\begin{array}{l}10^{7} \\
4 \times 10^{7} \\
10^{8}\end{array}$ & $\begin{array}{l}2.915 \\
2.83 \\
2.77\end{array}$ & $\begin{array}{l}.092 \\
.079 \\
.072\end{array}$ & $\begin{array}{l}.063 \\
.059 \\
.053\end{array}$ & $\begin{array}{l}7.80 \\
8.40 \\
8.8 v\end{array}$ & .099 \\
\hline
\end{tabular}
having negligible d-c conductivity (tables 1 and 2). In each case the calculated values of $\epsilon^{\prime \prime}$, which can be obtained for points at least one decade interior

TABLE 1. Electrical properties of Butvar 1

1 Data were obtained on a 3-terminal Schering bridge at frequencies of $10^{2}$ to $10^{5}$ $\mathrm{c} / \mathrm{s}$ and by resonance methods from $10^{3}$ to $10^{2} \mathrm{c} / \mathrm{s}$.

2 J. D. Ferry and E. R. Fitzgerald (reported before the American Physical Society in March 1952 at Columbus, Obio) have also made similar calculations, but use the cut-off approximation for both real and imaginary parts and then apply a second approxim
distribution function. 
TABLE 2. Electrical properties of copolymer $S M-2{ }^{1}$

\begin{tabular}{|c|c|c|c|c|c|}
\hline Frequency & $\epsilon^{\prime}$ & $\epsilon^{\prime \prime}$ & $Y$ & $-\log \tau$ & $\begin{array}{l}\epsilon^{\prime \prime}(\text { cal- } \\
\text { culated) }\end{array}$ \\
\hline $\begin{array}{l}10^{2} \quad c / s \\
10^{3}-\ldots \\
10^{4}-\cdots \\
10^{5}-\ldots \\
10^{6}\end{array}$ & $\begin{array}{l}3.090 \\
2.990 \\
2.898 \\
2.815 \\
2.740 \\
2.679\end{array}$ & $\begin{array}{r}0.0667 \\
.0705 \\
.0681 \\
.0605 \\
.0504 \\
.0400\end{array}$ & $\begin{array}{r}0.0443 \\
.0417 \\
.0399 \\
.0360 \\
.0303 \\
.0217\end{array}$ & $\begin{array}{l}2.80 \\
3.80 \\
4.80 \\
5.80 \\
6.80 \\
7.80\end{array}$ & $\begin{array}{r}0.068 \\
.064 \\
.058 \\
.046 \\
-.-\end{array}$ \\
\hline
\end{tabular}

${ }^{1}$ Data were obtained on a three-terminal Schering bridge at frequencies of $10^{2}$ to $10^{5} \mathrm{c} / \mathrm{s}$ and by resonance methods from $10^{5}$ to $10^{8} \mathrm{c} / \mathrm{s}$.

to the frequency limits, agree within 10 percent or better with the experimental ones, a discrepancy that can be accounted for by the graphical error. This suggests that the method described is applicable to polar polymers in the region in which they undergo orientation polarization, if the dispersion range is wide. It should be possible to deal with nonpolymeric materials in the same way, provided their electrical behavior meets these requirements.
The author has profited from discussions with R. S. Marvin and R. G. Breckenridge.

[1] B. Gross, Phys. Rev. 59, 748 (1941).

[2] R. M. Fuoss and J. G. Kirkwood, J. Am. Chem. Soc. 63, 385 (1941).

[3] J. R. MeDonald, J. Chem. Phys. 20, 1107 (1952).

[4] T. Alfrey Jr., Mechanical behavior of high polymers (Interscience Publishers, New York, N. Y., 1948).

[5] D. G. Ivey, B. A. Mrowca, E. Guth, J. Applied Phys. 20, $486(1949)$.

[6] A. W. Nolle, J. Polymer Sci. 5, 1 (1950).

[7] J. D. Ferry, W. M. Sawyer, G. V. Browning, A. H. Groth, J. Applied Phys. 21, 513 (1950).

[8] P. Debye, Polar molecules (Dover Publishers, New York, N. Y.).

[9] H. Fröhlich, Theory of dielectrics, p. 92 to 94 (Oxford Univ. Press, 1950).

[10] K. S. Cole and R. H. Cole, J. Chem. Phys. 9, 341 (1941).

[11] A. H. Scott, J. H. Beardsley, P. Ehrlich, E. C. Bamberger and D. R. Tilley, Unpublished data, obtained in Divs. 1 and 14 of NBS under the supervision of A. H. Scott and J. L. Dalke.

Washington, May 20, 1952. 